\author{
УДК 81'38 \\ ББК 81 \\ DOI: https://doi.org/10.17308/lic.2021.3/3581
}

\title{
ПОЛИПАРАДИГМАЛЬНОЕ ИССЛЕДОВАНИЕ КОННОТАЦИИ
}

\author{
О. И. Быкова \\ Воронежский государственный университет
}

\section{POLYPARADIGMAL RESEARCH OF CONNOTATION}

\author{
O. I. Bykova \\ Voronezh State University
}

\begin{abstract}
Аннотация: рассматривается необходимость полипарадигмального исследования многомерного лингвопсихологического феномена «коннотация», двойственная природа которого онтологически заключается во взаимодействии экстралингвистических и лингвистических факторов хранения и функционирования языковых единиц в определенном культурном пространстве. Семиотический, лингвокогнитивный и когнитивно-дискурсивный подходы ориентированы на выявление особенностей классификации, категоризации мира и репрезентации глубинных структур национального языкового сознания. Методологической базой исследования коннотации является семиотический подход. Динамическая модель коннотации по У. Эко представляет собой результат бесконечного семиозиса. Согласно гипотезе нашего исследования отмечается различная степень интерпретируемости оязыковленной информации, мотивация образной составляющей в кодах культуры. Концептуальная деривация и различные способы ее проявления при формировании новых смыслов лежат в основе взаимодействия мыслительных и языковых структур знаний немеикой лингвокультурной общности. Дискурсивная обусловленность проявления коннотативности проиллюстрирована в религиозном дискурсе. Теоретические и практические аспекты, результать полипарадигмального исследования коннотации имеют особую значимость при решении проблем межкультурной коммуникации, сопоставительных исследований и перевода.
\end{abstract}

Ключевые слова: коннотация, код, концептуальная деривация, концепт, дискурс.

\begin{abstract}
: the article considers the need for a multi-paradigm study of the multidimensional linguistic-psychological phenomenon "connotation", the dual nature of which ontologically consists in the interaction of extralinguistic and linguistic factors of the storage and functioning of language units in a certain cultural space. Semiotic, linguocognitive, and cognitive-discursive approaches are focused on identifying the features of classification, categorization of the world, and representation of the deep structures of national linguistic consciousness. The methodological basis of connotation research is the semiotic approach. A dynamic model of connotation in $U$. Eco is the result of infinite semiosis. According to the hypothesis of our study, there is a different degree of interpretability of the linguistic information, the motivation of the figurative component in the codes of culture. Conceptual derivation and various ways of its manifestation in the formation of new meanings are the basis for the interaction of thought and language structures of knowledge of the German linguistic and cultural community. The discursive conditionality of the manifestation of connotativity is illustrated in religious discourse. Theoretical and practical aspects, the results of the polyparadigmatic study of connotation are of particular importance in solving the problems of intercultural communication, comparative studies and translation.
\end{abstract}

Key words: connotation, code, conceptual derivation, concept, discourse.

\section{Введение}

Коннотация - специфическая семантическая категория, одна из наиболее проблемных в лингвисти- ке. Продолжение и развитие теории коннотации базируется на обобщении фактов семиотики, когнитологии, психолингвистики, лингвистики, культуроло-

(С Быкова О. И., 2021

Контент доступен под лицензией Creative Commons Attribution 4.0 License.

The content is available under Creative Commons Attribution 4.0 License. 
гии, прагматики. Двойственная природа коннотации проявляется в результате взаимодействия экстралингвистических и лингвистических факторов функционирования языковых единиц в деятельности говорящего. В разработке теории значения слова остается проблемной трактовка сущности коннотативных компонентов значения, их места в семантической структуре слова, их влияния на сферу функционирования номинативных средств, используемых коммуникантами в различных дискурсивных условиях. В исследовании коннотации как многомерного, многофункционального лингвопсихологического феномена открытыми вопросами остаются: определение лингвистического статуса, гетерогенная структура и типология коннотации. Ее сущность, роль в процессах межличностной коммуникации заключается в следующем: 1) она управляет коммуникацией; 2) может способствовать ей, нарушать ее. Главная трудность в толковании самого термина может быть объяснена: а) объективным моментом, идущим от сложности самого термина; б) субъективным моментом, связанным с позицией исследователей. Основной причиной расплывчатости дефиниции является ее двойственная природа: лингвистическая и экстралингвистическая. Ограниченные возможности объективного описания и экспликации емкого понятия «коннотация» только лингвистическими способами являются, с одной стороны, причиной кажущейся эклектичности интерпретации этого понятия различными науками, а с другой - обусловливают необходимость поиска онтологической сущности коннотации. Поиски критериев для уточнения термина «коннотация» определяются следующими направлениями: 1) онтология коннотаций; 2) методологический подход при определении ее содержательной структуры; 3) креативность и динамизм в синхронии и диахронии как свидетельство открытости семантической структуры лексических единиц. В условиях мультилингвизма и мультикультурализма и приоритетности признания антропоцентричности и системности языка осуществляется поиск специфики проявления человеческого сознания во многих языковых сферах и категориях.

В нашем определении коннотация - это многомерный, дополнительный макрокомпонент значения номинативных единии, мотивированный ассочиативным переосмыслением денотативного аспекта значения в категориях определенной культуры, представленный совокупностью оченочных, эмотивных, экспрессивно-образных и функционально-стилистических сем, которые отражают отночение говорящуего к обозначаемому, коммуникативной ситуации, и, в зависимости от интенциии говорящчего, способны кмодификации [1, с. 33-34].
Онтологические характеристики понятия «коннотация»: категории философии «имманентное», т. е. «пребывающее внутри, в самом себе», «посюстороннее» и «трансцедентальное»: «потустороннее», «лежащее за пределами доступного», составляют основу человеческого бытия и отражают глубинные структуры национального самосознания. Трансцендентное рассматривается как необходимая структура современной онтологии. Трансцендентное заявляет о себе в духовном опыте человека и как уровень онтологического позволяет человеку увидеть в бытии нечто глубинное. В коннотации проявляется интерпретативный характер переосмысления объекта из мира «действительного».

\section{Материалы и методы исследования}

Учитывая, что основным объектом для различных аспектов одной широкой антропоцентрической парадигмы является человек, и каждое из направлений дисциплин, исследующих коннотацию, претендует на самостоятельный научный статус, есть основания, как отмечает Ю. М. Малинович, констатировать полипарадигмальность современного языкознания. В его монографии дано обоснование статуса антропологической лингвистики как интегральной науки, базовыми понятиями которой являются человек и язык в их нерасторжимом единстве в его однозначной формулировке «человек в языке» [2].

\section{Семиотический подход как методологическая база исследования коннотации}

Исходя из понимания комплексного характера коннотации как специфической семантической категории выражения отношения пользователя языком (интерпретатора) к языку в процессе вторичного лингвосемиозиса и интерпретируемости, как свойства знака содержать интерпретанту, функционирующую в определенной культуре, правомерно считать методологической базой исследования коннотации: 1) специфику семиотического представления о языке как кодирующем устройстве, отражающем форму анализа реальной действительности; 2) теоретические положения о взаимодействии языковых, когнитивных, коммуникативных факторов функционирования и эволюции языка. Процесс понимания мира, образования выводных знаний при осмыслении окружающего, как и при осмыслении текста или дискурса, - инференционный процесс, «требующий семиотической компетентности людей» [3, с. 97]. Особо следует отметить значимость семиотики У. Эко. В теоретическом плане она заключается в междисциплинарной установке на исследование культурно обусловленного функционирования знако- 
вых систем (кодов) в различных социальных условиях проявления активности человека [4, S. 98]. Переход от мира сигнала к миру смысла означает, что человек, являющийся источником и передатчиком информации, осуществляет идентификацию смыслоразличительных признаков, согласно заложенному коду [5, с. 47]. Благодаря коду определенное означающее связывается с определенным означаемым: «коннотативное значение рождается именно тогда, когда означающее и означаемое формируют пару, которая становится означающим нового означаемого» [Там же, с. 54]. Динамическая модель коннотаций, предложенная У. Эко, представляет собой цепь интерпретант, возникающих в результате бесконечного семиозиса. Первичная коннотация, порождаемая первичной денотацией в результате преобразования прежних коннотаций, «в которой уже вновь сложившийся знак весь целиком выступает в роли нового означающего» [Там же]. В процессе вторичной семиотизации в смысловой структуре знания происходит транспозиция (выделено нами. - O. Б.) кодовых элементов: погашение предметно-практических смыслов и порождение смыслов, возникающих в системе жизненно значимых отношений человека и среды его обитания. С позиций бесконечного семиозиса денотация, по У. Эко, только определяет позицию лексемы в семантическом пространстве определенной культуры, в то время как все богатство процесса коммуникации опирается на целое множество, последовательность (сеть) интерпретант, посредством которых процесс семиозиса как бы придает лексеме собственную жизнь. Денотация непосредственно соотнесена с кодом, который приписывает форму выражения к определенной культуре. А коннотация - это сумма всех культурных значимостей, которые сигнификат может вызвать институционально в памяти получателя информации. Такое толкование коннотации У. Эко следует из его функционально обусловленного подхода к культуре как особой коммуникации, которая может быть основательно изучена, по его мнению, только с точки зрения семиотического подхода. Преобразование прежних означающего и означаемого в новое означающее может породить новую, вторичную номинацию.

Понятие код пришло в лингвистику из теории информации, где код определяется как механизм соединения двух наборов сигналов недвусмысленным, обратимым и независимым от контекста способом: «a code is a mechanism to pair two sets of signals in nonambiguous, reversible and context-free way» [6, p. 23]. В самом определении кодовой модели общения заложена идея интенциональности, интерпретативности и открытости кодовых операций. В этнолингвистических исследованиях широко используется понятие кода, которое при анализе мотивационного уровня культурно обусловленных значений при выходе за рамки языковой системы оказывается прямым продолжением или расширением лингвистического понятия мотивации. Мы разделяем понимание кода культуры с позиций когнитивной лингвистики: как «сетки», которую культура «“набрасывает” на окружающий мир, членит, категоризирует, структурирует и оценивает его» [7, с. 232].

С точки зрения универсальной природы кодов культуры большинство исследователей выделяют в качестве базовых кодов культуры: антропоморфный, вещный (предметный), акциональный, пространственный, временной, соматический (телесный), биоморфный (зооморфный и флороморфный), числовой, цветовой (хроматический), густический (вкуca), одорический (запаха), ономастический (именной), духовный. Все коды культуры участвуют в структурации и оценке материального мира лингвокультурной общностью, так как образуют систему координат, которая содержит и задает эталоны культуры. Особую значимость имеет духовный код культуры: 1) он изначально аксиологичен, так как связан с системой нравственных ценностей, проявляющихся в эталонах, стереотипах поведения говорящих; 2) на него «работают» все коды культуры; 3) имеет специфические способы проявления в субкодах (мифологема, фольклор, обряд, ритуал). Код культуры выполняет роль фильтра при мотивации выбора признака внутренней формы знака. Наличие различных векторов ассоциаций при вторичной номинации знаков особо значимо при сопоставлении интерпретативной направленности знаковых функций реалий различных культур.

Мы полагаем, что «релевантность количественных и качественных характеристик кодирования определяет уникальность признаков коннотатов, вызываюших в сознании говорящего отнесенность языкового знака к определенному культурному пространству, специфику культурной маркированности коннотированных единиц лексического и фразеологического фондов языка» [8, с. 30].

По способу фиксации образно-мотивирующего признака для отдельных групп вторичных номинант характерна различная степень участия кодов культуры. Доказуемость данного постулата была подтверждена результатами нашего исследования немецкоязычного культурного пространства. Наибольшую степень интерпретируемости оязыковленной культурно значимой информации кодами культуры обнаружили прагматонимы (7 кодов): обозначения денотатов в прагматической сфере деятельности человека - предметы домашней утвари, мебель, продукты питания, точки питания, одежда ${ }^{1}$. Признак коннотата

${ }^{1}$ В качестве условных обозначений используются: Д денотативное значение и К - коннотативное значение. 
вторичных прагматонимов фиксируют следующие коды культуры: 1) духовный: Д1 Thors Hammer, молот бога-громовика Тора, К1 - удар грома; 2) акциональный: Д1 das Hämmerlein, молоточек, К1(1) Meister Hämmerlein - полтергейст, К1(2)-смерть, К1(3) - палач; 3) флороморфный: Д1 der Senf, горчицза, К1 - длинная речь, пустое высказывание; 4) предметный: Д1 die Kommode, комод, вид секционной мебели, К1 - библиотека Берлинского университета; 5) цветовой: Д1 das Rotkäppchen, головной убор красного извета, К1(1) - проводник поезда, дежурный по вокзалу, К1(2) - французский солдат во время правления Наполеона III, К1(3) - стюардесса авиакомпании Люфтганза; 6) одорический: Д1 der Limburger, лимбургский сыр с сильным запахом, К1(1) - неприличная шутка, сальность, К1(2) - потливые ноги; 7) вещественный: Д1 die Kohle, уголь, К1 die Kohlen (Pl.), деньги. Ассоциативное переосмысление денотативного содержания (Д) при вторичном именовании (К) прагматонимов обусловлено знаковой сущностью артефактов (предметов домашней утвари, мебели, одежды, продуктов питания, точек питания), обладающих этноспецифической символической значимостью и многоплановостью их семиотических функций.

\section{Лингвокогнитивный подход}

Скрытые глубинные механизмы познавательной деятельности и принадлежащие глубинным уровням психики человека содержательные категории, составляющие предпосылку его деятельности, являются объектом когнитивной лингвистики. С точки зрения референции языковых знаков к концептам, номинанты репрезентируют осмысление мира, его конструирование языковым коллективом, интерпретирующим содержание тела знака, под который подводится концепт. Они по-разному принимают участие в категоризации и концептуализации фрагментов действительности. Так в немецкоязычном культурном пространстве по степени активности участия в номинации концептов нами выделены коннотированные антропонимы (18 концептов) и прагматонимы (14 концептов), самобытность и оригинальность которых отчетливо проявилась в многосторонней квалификации явлений реального и вымышленного мира в языковом сознании носителей языка. По номинативной вариативности самыми актуальными оказались концепты «черты характера и манера поведения человека» $(31,8$ \%). Множественная вариативность выявлена в концептах, связанных с человеком как ключевым макроконцептом культуры: «профессия и род занятий», «внешность человека» и «социальный статус». Формирование нового смысла, порождение коннотации в результате интерпретации исходного вербализованного знания осуществляется в процессе концептуальной деривации. В самом определении концептуальной деривации, данном Н. Н. Болдыревым, выделена сущность взаимодействия мыслительных и языковых структур: «<...> концептуальная деривация - это языковая модель изменения определенного концептуального содержания с целью формирования нового смысла» (выделено Н. Н. Болдыревым) [9, с. 47-48]. Вторичная языковая интерпретация основывается на вторичной концептуализации знаний о мире, «процессах порождения новых знаний на базе существующих концептов, что можно рассматривать как процессы концептуальной деривации» [10, с. 39]. В качестве способов проявления концептуальной деривации на языковых уровнях (семантической, словообразовательной деривации и фразеологизации) выступают механизмы профилирования, концептуальной интеграции и частных проявлений концептуальной деривации: метафоризации, метонимизации и метафтонимизации. Это представляет собой перспективу для исследований взаимодействия когнитивных и языковых механизмов актуализации культурно обусловленных коннотативно маркированных смыслов высказывания.

\section{Когнитивно-дискурсивный подход}

Для когнитивно-дискурсивной парадигмы важно интегральное описание когнитивных и коммуникативных особенностей бытия языка (способ употребления языка). Дискурсивная деятельность осуществляется в рамках социального контекста с учетом всех прагматических свойств адресата. Языковые формы дискурса выражены на трех уровнях: 1) семантическом (обозначение объектов и обстоятельств действия); 2) прагматическом (установление намерений говорящего; 3) интеракциональном (по последствиям для поведения партнеров по речи) [11, с. 530]. На выбор определенных языковых средств, используемых в социуме или культуре для репрезентации конкретной концептуальной области и интерпретации смысла, влияет присутствующее в дискурсе указание, когнитивно-дискурсивная интерпретанта [12, c. 410]. Прагматика и семантика не могут быть строго отграничены друг от друга, так как теория аргументативной прагматики интегрирована в семантике языковых единиц, т. е. речь идет о взаимообусловленности макроструктур дискурсов (например, религия), типов текстов, микроструктур. Изучение дискурсивно обусловленных языковых сущностей, форма и содержание которых не только определяются дискурсом, но и одновременно являются заданностью (нем. Vorgabe) дискурса, и предполагает, что вариативность языковых, текстотипологических и дискурсивных 
объектов может быть объяснена, исходя из их (языковых сущностей) значения (инвариантности). В трактовке немецкого исследователя Хольгара Кусce это явление обозначено как «partieller Kontextualismus» [13, S. 98]. Дискурс является сферой коммуникации, в которой проявляются и упорядочиваются ценностные ориентиры, нормы и направленность действия, а также формы осуществления действий коммуникантов.

Проиллюстрируем дискурсивную обусловленность проявления коннотативности в немецкоязычном религиозном дискурсе, служащем для усиления существующего убеждения и включающем 2 вида дискурса: 1) мифический (притчи) и 2) космологический. Религия выступает как определенная форма знаний о смысле существования мира и собственной жизни человека. В религиозном дискурсе можно обнаружить аксиологическую оппозицию: область трансцендентного (невидимый мир) имеет положительную оценку, а видимый мир (собственно персона, общество) - отрицательную оценку. Наиболее частотным механизмом порождения образной экспрессивности является метафора: Lamm Gottes, агнец, кроткое существо, символ жертвенности Христа; der Äon, вечность. Релевантна оппозиция оценки: das Licht, свет; die Höhe, выссота - маркированы положительной оценкой; die Schlange, змей-искуситель, дьявол - отрицательной оценкой. Оппозиция функционально-стилистической маркировки (функциолект): verheißen, дать обет (сакрально) и versprechen, обещать (нейтрально-литературный). Характерна религиозно мотивированная диглоссия при метафоризации, например, при обозначении пространства: oben, рай - unten, ад, преисподня.

\section{Выводы}

Таким образом, полипарадигмальное исследование коннотации позволяет целенаправленно и адекватно выявлять отражение глубинных структур национального языкового сознания, взаимодействие когнитивных и языковых механизмов порождения коннотации вторичными номинантами в результате концептуальной деривации в дискурсивных практиках.

Дальнейшее рассмотрение теоретических и практических аспектов как способов проявления интерпретируемости мира в первовидении носителями национального языка могут быть учтены в контексте теории и практики межкультурной коммуникации, сопоставительных исследований и перевода.

\section{ЛИТЕРАТУРА}

1. Быкова О. И. Этноконнотация как вид культурной коннотации : на материале номинативных единиц не- мецкого языка. Воронеж : Воронежский государственный университет, 2005. 277 с.

2. Малинович Ю. М., Малинович М. В. Антропологическая лингвистика как интегральная наука // Антропологическая лингвистика. Концепты. Категории. М. ; Иркутск, 2003. С. 7-28.

3. Кубрякова Е. С. О семиотически маркированных объектах и семантически маркированных ситуациях в языке // Концептуальное пространство языка : сб. науч. трудов. Тамбов : Изд-во ТГУ им. Г. Р. Державина, 2005. C. $95-101$.

4. Eco U. Semiotik. Entwurf einer Theorie der Zeichen. München : Fink, 1987. 439 S.

5. Эко У. Отсутствующая структура. Введение в семиологию. СПб. : Петрополис, 1998. 430 с.

6. Key Terms in Language and Culture / ed. by A. Duranti. Malden, Massachusetts, USA : Blackwell Publishers, 2001. 282 p.

7. Красных В. В. Этнопсихолинвистика и лингвокультурология : курс лекций. М. : Гнозис, 2002. 284 с.

8. Быкова О. И. Этнолингвосемиотический подход к исследованию коннотации // Филология и культура. Philology and Culture. 2012. № 2 (28). C. 28-31.

9. Болдырев Н. Н. Оценочная метарепрезентация : проблемы изучения и описания // Когнитивные исследования языка : сб. науч. трудов. Вып. V: Исследование познавательных процессов в языке. М. ; Тамбов, 2009. C. $43-51$.

10. Болдырев Н. Н. Концептуальная деривация как основа вторичной языковой интерпретации // Когнитивные исследования в гуманитарных науках : материалы Всерос. науч. конф. с междунар. участием. Вып. XXXIII. 17-18 мая 2018 г. / отв. ред. вып. Л. В. Бабина. Тамбов : Принт-Сервис, 2018. С. 37-41.

11. Кубрякова E. C. Язык и знание : на пути получения знаний о языке : части речи с когнитивной точки зрения. Роль языка в познании мира / Рос. академия наук. Ин-т языкознания. М. : Языки славянской культуры, 2004. 560 с. (Язык. Семиотика. Культура).

12. Болдырев Н. Н. Язык и система знаний. Когнитивная теория языка. 2-е изд. М. : ЯСК, 2019. 480 с.

13. Кuße H. Kulturwissenschaftliche Linguistik. Eine Einführung. Göttingen, 2012. S. 97-100.

\section{REFERENCES}

1. Bykova O. I. Ètnokonnotaciâ kak vid kul'turnoj konnotacii: na materiale nominativnyh edinic nemeckogo jâzyka [Ethnoconstruction as a type of cultural connotation: on the material of nominative units of German]. Voronezh: Voronezh State University, 2005. 277 p.

2. Malinovich YU. M., Malinovich M. V. Antropologicheskaya lingvistika kak integral'naya nauka [Anthropological linguistics as an integral science]. In: Antropologicheskaya lingvistika. Kontsepty. Kategorii [Anthropological linguistics. Concepts. Categories]. M., Irkutsk, 2003. Pp. 7-28.

3. Kubryakova E. S. O semioticheski markirovannykh ob"ektakh i semanticheski markirovannykh situatsiyakh $v$ 
yazyke. [On semiotically marked objects and semantically marked situations in the language]. In: Kontseptual'noe prostranstvo yazyka: Sb. nauch. tr. [Conceptual Space Language: Sat. Scientific Tr.]. Tambov: Publishing House of TSU G. R. Derzhavina, 2005. Pp. 95-101.

4. Eco U. Semiotik. Entwurf einer Theorie der Zeichen. München : Fink, 1987. 439 p.

5. E`ko U. Otsutstvuyushhaya struktura. Vvedenie v semiologiyu [The missing structure. Introduction to semiology]. St. Petersburg: Petropolis, 1998. 430 p.

6. Key Terms in Language and Culture. Edited by A. Duranti. Malden, Massachusetts, USA: Blackwel Publishers, 2001. 282 p.

7. Krasnykh V. V. EHtnopsikholinvistika i lingvokul'turologiya: kurs lektsij [Ethnopsycholismism and linguocultureology: course of lectures]. M.: Gnosis, 2002. 284 p.

8. Bykova O. I. EHtnolingvosemioticheskij podkhod $k$ issledovaniyu konnotatsii [Ethnoling-formemiotic approach to the study of connotation]. In: Filologiya i kul'tura. Philology and Culture. [Philology and culture. Philology and culture]. 2012. No. 2 (28). Pp. 28-31.

9. Boldy`rev N. N. Ocenochnaya metareprezentaciya: problemy izucheniya i opisaniya [Evaluation Molding: Problems of Study and Description]. In: Kognitivny'e issledovaniya yazy 'ka: issledova nie poznavatel 'ny ‘ x processov v yazy ke [Cognitive language studies: Sat. Scientific Labor. Vol. V.: The study of cognitive processes in the language]. M. ; Tambov, 2009. Pp. 43-51.

Воронежский государственный университет

Быкова О. И., профессор кафедры немечкой филологии

E-mail: bykowa.olga@rambler.ru

Поступила в редакичию 20 мая 2021 г.

Принята к публикачии 15 июня 20212.

\section{Для цитирования:}

Быкова О. И. Полипарадигмальное исследование коннотации // Вестник Воронежского государственного университета. Серия: Лингвистика и межкультурная коммуникация. 2021. № 3. C. 61-66. DOI: https://doi. org/10.17308/lic.2021.3/3581
10. Boldy`rev N. N. Konceptual naya derivaciya kak osnova vtorichnoj yazy kovoj interpretacii [Conceptual derivation as the basis of secondary language interpretation]. In: Kognitivny 'e issledovaniya $v$ gumanitarny'x naukax: materialy`Vserossijskoj nauchnoj konferencii s mezhdunarodny'm uchastiem. Vy'p. XXXIII. 17-18 maya 2018 g., otv. red. vy p. L. V. Babina. [Cognitive studies in the humanities: materials of the All-Russian Scientific Conference with international participation. Vol. XXXIII. May 17-18, 2018., answer ed. vol. L. V. Babina]. Tambov: Print-service, 2018. Pp. 37-41.

11. Kubryakova E. S. Yazy $k$ i znanie: Na puti polucheniya znanij o yazy 'ke: Chasti rechi s kognitivnoj tochki zreniya. Rol yazy $k a v$ poznanii mira [Language and knowledge: on the way of receiving knowledge about language: Parts of speech from a cognitive point of view. The role of the language in the knowledge of the world] / Ros. akademiya nauk. In-t yazy`koznaniya. M.: Yazy ki slavyanskoj kul 'tury', (Yazy 'k. Semiotika. Kul tura). M.: Languages of Slavic Culture, 2004. 560 p. (Language. Semiotics. Culture).

12. Boldy`rev N. N. Yazy`k i sistema znanij. Kognitivnaya teoriya yazy $k a$ [Language and knowledge system. Cognitive language theory]. 2nd ed. M. : Publishing House YaSK, 2019. 480 p.

13. Kuße H. Kulturwissenschaftliche Linguistik. Eine Einführung. Göttingen, 2012. Pp. 97-100.

Voronezh State University

Bykowa O. I., Professor of the German Philology Department

E-mail:bykowa.olga@rambler.ru

Received: 20 May 2021

Accepted: 15 June 2021

\section{For citation:}

Bykova O. I. Polyparadigmal research of connotation. Proceedings of Voronezh State University. Series: Linguistics and Intercultural Communication. 2021. No. 3. Pp. 6166. DOI: https://doi.org/10.17308/lic.2021.3/3581 